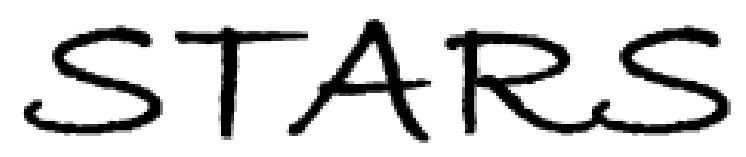

University of Central Florida

STARS

\title{
Effect of Various Speed Management Strategies on Bicycle Crashes for Urban Roads in Central Florida
}

Jorge Ugan

University of Central Florida

Part of the Civil Engineering Commons, and the Transportation Engineering Commons

Find similar works at: https://stars.library.ucf.edu/etd2020

University of Central Florida Libraries http://library.ucf.edu

This Masters Thesis (Open Access) is brought to you for free and open access by STARS. It has been accepted for inclusion in Electronic Theses and Dissertations, 2020- by an authorized administrator of STARS. For more information, please contact STARS@ucf.edu.

\section{STARS Citation}

Ugan, Jorge, "Effect of Various Speed Management Strategies on Bicycle Crashes for Urban Roads in Central Florida" (2021). Electronic Theses and Dissertations, 2020-. 940.

https://stars.library.ucf.edu/etd2020/940

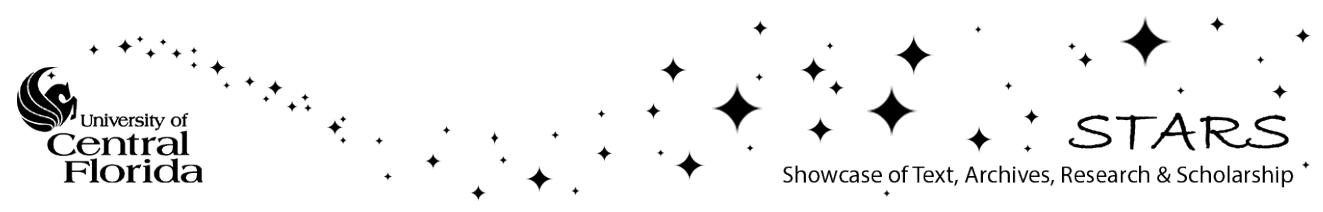




\title{
EFFECT OF VARIOUS SPEED MANAGEMENT STRATEGIES ON BICYCLE CRASHES FOR URBAN ROADS IN CENTRAL FLORIDA
}

\author{
by \\ JORGE ALEXANDER UGAN \\ B.Sc. University of Central Florida, United States, 2020 \\ A thesis submitted in partial fulfillment of the requirements \\ for the degree of Master of Science \\ in the Department of Civil, Environmental and Construction Engineering \\ in the College of Engineering and Computer Science \\ at the University of Central Florida \\ Orlando, Florida
}

Fall Term

2021

Major Professor: Mohamed Abdel-Aty 
(C) 2021 Jorge Ugan 


\begin{abstract}
In recent years, cycling has become an increasingly popular transportation mode around the world. In contrast to other popular modes of transportation, cycling is more economic and energy efficient. While many studies have been conducted for the bicycle safety analysis, most of them were limited in terms of bicycle exposure data and on-street data. This study tries to improve the current safety performance functions for bicycle crashes at urban corridors by utilizing crowdsource data from STRAVA and on-street speed management strategies data. Speed management strategies are any roadway alterations that causes a change in motorists' driving behavior. In Florida, these speed management strategies were defined by the Florida Department of Transportation (FDOT) Design Manual. Considering the disproportion in the representation of cyclists from the STRAVA data, adjustments were done to more accurately represent the cyclists based on the video detection data by developing a Tobit model. The adjusted STRAVA data was used bicyclist exposure to analyze bicycle crashes on urban arterials. A Bayesian joint model was developed to identify the relations between the bicycle crash frequency and factors relating speed management strategies. Other factors such as vehicle traffic data, roadway information, sociodemographic characteristics, and land use data were also considered in the model. The results suggested that the adjusted STRAVA data could be used as the exposure for bicycle crash analysis. Also, the results highlighted the significant effects of speed management strategies such as parking lots and surface pavement. It is expected that the results could help engineers develop effective strategies to enhance safety for bicyclists.
\end{abstract}

Keywords: Bicycle exposure; bicycle facility; bicycle safety; urban roads; roadway characteristics 


\section{ACKNOWLEDGMENT}

I would foremost like to extend my gratitude towards Dr. Mohamed Abdel-Aty for his assistance and guidance for the completion of this research project and for the opportunities that have come from being in Dr. Aty's research group. Throughout my research Dr. Aty has always been understanding, which has been greatly appreciated during this difficult time caused by the COVID-19 pandemic. Being a part of Dr. Aty's research group has brought about experiences, knowledge, and friendships that I am undoubtably grateful for.

Additionally, I would like to thank my colleagues who helped me with different steps of my research. Dr. Qing Cai for helping me formulate my research idea and for always being available to discuss any questions I had. I would also like to thank Dr. Pei Li, Dr. Shile Zhang, Dr. Lishengsa Yue, Dr. Nada Mahmoud, Amr Abdelraouf, Ahmed Kabli, Nami Al Sulami, Abdulrahman Faden, and Soliman Al Ahmadi for their help and advice throughout my research. Being part of the research group has allowed me to make friendships that I will always be thankful for.

I kindly acknowledge the financial support of the Florida Department of Transportation. I take responsibility for all opinions expressed in this study. The author acknowledges the financial support of the Florida Department of Transportation. All opinions expressed in this study are those of the authors and not the sponsor.

Finally, most of all, I would like to thank my family and friends from my hometown, Miami, Florida, for their endless support. I am grateful to my parents Beatrice Ugan and Jose Ugan, for giving me the opportunities and experiences that have made me who I am. I would also like to extend my deepest gratitude to my grandparents, Julia Ugan, Jorge Ugan, and Olga Bustamante for love and inspiration throughout my life. The most rewarding feeling has been to make them proud and contribute towards transportation safety. 


\section{TABLE OF CONTENTS}

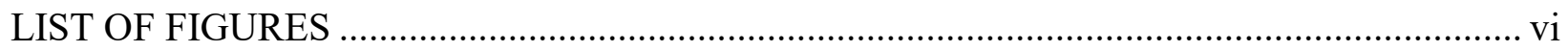

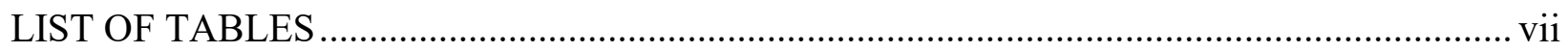

CHAPTER 1: INTRODUCTION ……………………………………………………….... 1

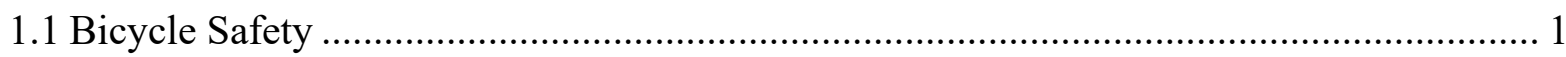

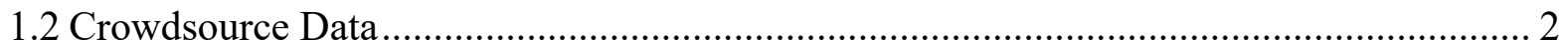

1.3 Speed Management Strategies …………………….............................................. 3

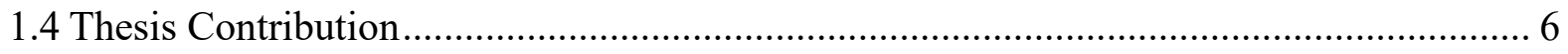

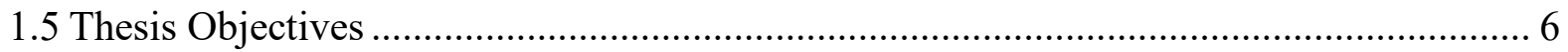

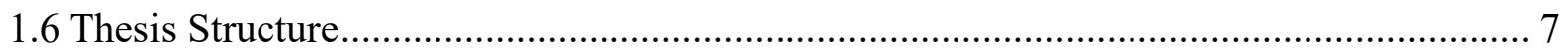

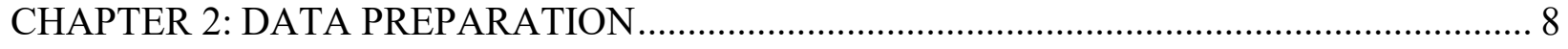

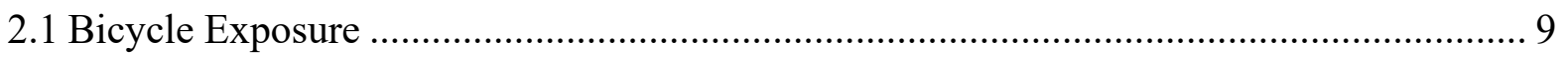

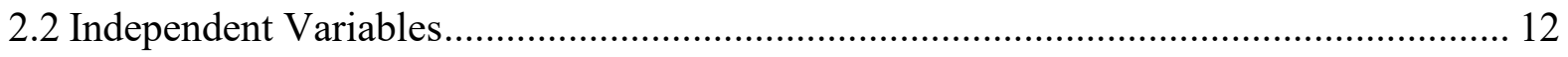

2.3 Speed Management Strategies Data.......................................................................... 14

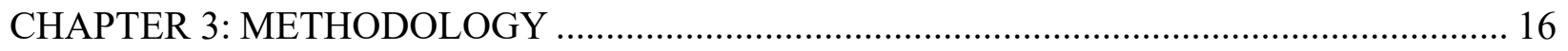

CHAPTER 4: MODELING RESULTS AND DISCUSSIONS ……….................................. 19

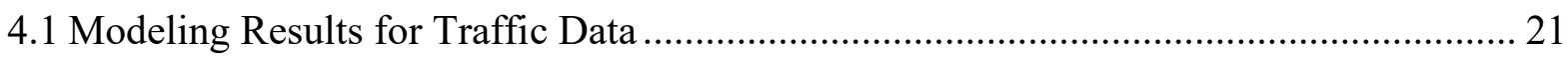

4.2 Modeling Results for Roadway Information ……………............................................. 22

4.3 Modeling Results for Speed Management …………….............................................. 22

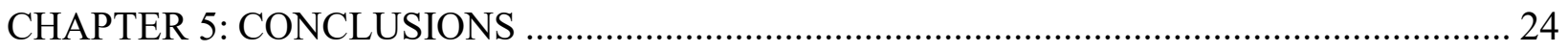

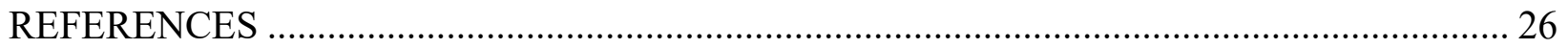




\section{LIST OF FIGURES}

Figure 1 Roads categorized into different context classifications ......................................... 8

Figure 2 Total cyclist trips from STRAVA between January 2018 to July 2018 _..................... 9

Figure 3 Calculation of bicycle volumes between Intersection 1 and 2 using video detection.... 11

Figure 4 Examples of different types of curb extensions ................................................ 15

Figure 5 Example of Two-Way Left-Turn Lanes .................................................................. 15

Figure 6 Relationship between the Tobit Model and Poisson Lognormal Model ...................... 20 


\section{LIST OF TABLES}

Table 1 Descriptive statistics for the variables .................................................................... 13

Table 2 Bayesian joint model, including the Tobit Model and Poisson Lognormal model ......... 21 


\section{CHAPTER 1: INTRODUCTION}

\subsection{Bicycle Safety}

With the growing popularity of cycling as a mode of transportation, there has been a demand for knowledge of urban cycling. This demand reflects the realization of the limitations of vehicle-dependent transport planning, in terms of congestion, parking problems, reduced levels of amenity and liveability, air pollution, resource depletion, and climate change (Fishman, 2016). However, bicycle safety is a major concern in urban cities, which may lead to a reduction of cyclists' activity. According to a report released from the National Highway Traffic Safety Administration, the cyclist deaths rose by 6.3 percent from 2017 to 2018 , despite the overall decrease of 2.4 percent in total motor vehicle accident deaths (NHTSA, 2019). The report also revealed that since 2009 , the number of cyclist fatalities in urban areas has risen by 48 percent. Meanwhile, cyclist fatalities in rural areas over the same period decreased by 8.9 percent. To propose effective strategies to improve bicycle safety, it is important to reach an understanding of the contributing factors behind bicycle crash occurrences by conducting bicycle safety studies.

Many studies have identified different types of road characteristics that have continuously been related to bicycle crashes (Cai, Abdel-Aty, \& Castro, 2020; Cai, Lee, Eluru, \& Abdel-Aty, 2016; Kondo, Morrison, Guerra, Kaufman, \& Wiebe, 2018; Morrison, Thompson, Kondo, \& Beck, 2019; Saad, Abdel-Aty, Lee, \& Cai, 2019; Siddiqui, Abdel-Aty, \& Choi, 2012). Siddiqui et al. utilized Bayesian models to estimate bicycle crashes according to the presence of roadway characteristics in Florida, United States (Siddiqui et al., 2012). The authors have identified that a non-linear relationship exists between the traffic load and crash occurrence. Schepers and Brinker explained that the dearth of data might be a reason to why not many studies have been on single-bicycle crashes in relation to road characteristics (Schepers \& den Brinker, 2011). 
Some studies that have been done performed a questionnaire study to the victims involved in the crashes to evaluate the road factors that contributed to the crash. A study showed that poor roadway maintenance contributed to $51 \%$ of the crashes studied (Nyberg, Björnstig, \& Bygren, 1996). Cai et al. performed a zero-inflated negative binomial spatial model, identifying several factors that have a significant impact on bicycle crashes. Some of the factors that were identified were daily motor vehicle volume, bicycle volume, number of lanes, and land use (Cai et al., 2016).

One of the key elements that is used to predict bicycle crashes is exposure. Many studies calculate exposure in different ways (Hamann \& Peek-Asa, 2013; Saha, Alluri, Gan, \& Wu, 2018). Exposure can be bicycle volumes, motor vehicle volumes, bicycle trip miles, etc. Vanparijs et al. emphasized the importance of the bicycle exposure for bicycle safety analysis (Vanparijs, Panis, Meeusen, \& de Geus, 2015). However, as Schepers and Brinker mentioned there is a deficiency of accurate bicycle exposure measures. Ding et al. utilized bicycle trip data of a public bicycle rental system in Greater London to proxy bicycle exposure (Ding, Sze, Li, \& Guo, 2020). The study looked into using three different types of bicycle exposure; population, bicycle use time, and bicycle use frequency. Using bicycle use time as the exposure gave a better goodness of fit. Through the use of Geographical Information System (GIS) the authors were able match the wide range bicycle exposure data.

\subsection{Crowdsource Data}

The difficulty of obtaining accurate bicycle data for estimating bicycle traffic volume has been reported in many studies (Griffin \& Jiao, 2019; Griswold, Medury, \& Schneider, 2011; Hochmair, Bardin, \& Ahmouda, 2019; Jestico, Nelson, \& Winters, 2016). Typically, bicycle data 
can be collected through crowdsources GPS trackers, video detection cameras, automated counters, observed data, or travel surveys (Blaizot, Papon, Haddak, \& Amoros, 2013). Each of the different measures used to collect bicycle data has different limitations, accuracies, and cost. Taking these different factors into consideration, it was determined that crowdsource GPS trackers are more preferred due to the low cost, accuracy, and wide range of cyclists when compared to the other bicycle volume measures. Crowdsource GPS applications, such as STRAVA, MapMyRide, and MyTracks are considered to be Big Data sources. STRAVA is a smart phone application that depends on GPS data to gather and record runners' and cyclists' activities. STRAVA has more than 50 million users worldwide, and about 1 million users join each month. Since the founding of STRAVA in 2009, there has been more than 3 billion total activities that have been uploaded (STRAVA, 2020). This abundance of temporal and spatial data has potential to be used for analyzing bicycle safety. Although, some studies have shown skepticism towards utilizing STRAVA data for representing the actual proportion of cyclists in a population (Griffin \& Jiao, 2019; Hochmair et al., 2019; Jestico et al., 2016).

\subsection{Speed Management Strategies}

The FDOT Design Manual (FDM) divides roads in Florida into different context classification. A context classification is a design control that dictates key design criteria elements for roadways. Roads in Florida are assigned to a context classification based on the roadway characteristics and criteria. In general, context classification includes eight different categories: C1-Natural, C2-Rural, C2T- Rural Town, C3R-Suburban Residential, C3C- Suburban commercial, C4-Urban General, C5-Urban Center, and C6-Urban Core (FDOT, 2020a).

Speed management strategies that could be implemented to achieve target speed on context classifications are based on national practices for low speed facilities. These strategies are can be 
utilized on roadways when consistent with the context classification of the roadway. The proposed strategies in FDM follow one of three main concepts: Enclosure, Engagement, and Deflection. Enclosure is one of the speed management approaches that enhance the drivers' sense of speed by providing the feeling that the roadway is contained. Examples of Enclosure are using street trees, buildings close to the streets, and on-street parking. The second concept is Engagement, and it focuses on connecting the driver with the surrounding environment through visual and audial interventions. This concept includes architectural details, shop windows, onstreet parking, and presences of pedestrians. The third concept is Deflection, which deviates the driver from the intended path using vertical or horizontal movement. This is considered as one of the most powerful speed management approaches. Deflection includes roundabouts, splitter medians, and raised intersections (Bauer, Harwood, Hughes, \& Richard, 2004; FDOT, 2020b; FHWA, 2014a; Petritsch, 2009).

On-street parking are parking lanes that are adjacent to the travel lane is one of the effective speed management strategies. It maximizes the engagement between the parking lane and the travel lane. However, when using on-street parking as a speed management countermeasure, bicycle lanes shouldn't be installed between travel lane and parking lane. Previous studies have found that the presence of on-street parking proposes a hazard for cyclists (Biswas, Chandra, \& Ghosh, 2017; J. Chen, Li, Wang, \& Jiang, 2018; DiGioia, Watkins, Xu, Rodgers, \& Guensler, 2017; Schimek, 2017, 2018). Schimek concluded that the dooring problem is not known since most data sources exclude this type of incident, and states that dooring incidents are one of the most causes of urban bicycle-motor vehicle crashes, accounting for $12 \%$ to $27 \%$ of the total (Schimek, 2017). 
A road diet is removing travel lanes from a roadway and utilizing the space for other uses and travel modes. The most common road diet configuration is converting four-lane undivided roads into three lanes (two through lanes plus a center turn lane). Furthermore, reduction of lanes could be beneficial in reallocating the roadway for other uses such as bike lanes, pedestrian refuge islands, transit uses, and/or parking (FHWA, 2014b; Neuner et al., 2015; Tan, 2010). Previous studies have shown there to be a reduction in bicycle crashes with the implementation of road diets (L. Chen et al., 2013; Gates, Noyce, Talada, \& Hill, 2007; Noland, Gao, Gonzales, $\&$ Brown, 2015). Chen et al. analyzed safety countermeasures in New York City, and found that the implementation of road diets is highly effective, reducing "segment-based crashes significantly-total crashes by $67 \%$, vehicle crashes by $67 \%$, and injurious and fatal crashes by 70\%” (L. Chen et al., 2013). Hamann and Peek-Asa analyzed the relationship between on-road bicycle facilities and bicycle crash in Iowa from 2007 to 2010 . The study revealed that for every 10-foot increase in the width of the roadway, the odds of the roadway having a bicycle crash increased by $38 \%$. Therefore, the results suggest that reducing the width of the roadway may be associated with a decreases risk for bicycle crashes (Hamann \& Peek-Asa, 2013).

Road pavement has also been known to be a factor in bicycle safety. Robartes and Chen examined bicyclist, automobile driver, vehicle, environmental, and roadway characteristics that influence cyclist injury severity on roads in Virginia. The paper concluded that pavement surfaces that are not smooth are less likely to be involved in fatal, severe, and minor injury crashes, with probabilities decreasing by $0.0030(-90.1 \%), 0.1255(-69.3 \%)$, and 0.1247 (-21.6\%), respectively (Robartes \& Chen, 2017). Kim J-K et al. explores the factors contributing to the injury severity of bicyclists in bicycle-motor vehicle accidents using a multinomial logit model on roads in North Carolina. The study found that the most common road class type and 
road surface type were local streets $(60.8 \%)$ and asphalt roads $(97.7 \%)$ (J.-K. Kim, Kim, Ulfarsson, \& Porrello, 2007). Dozza and Werneke shows how naturalistic cycling data from 16 bicyclists can be used to estimate risk while cycling. The study found that the risk of experiencing a critical event on an asphalt surface to be $85.7 \%$ (Dozza \& Werneke, 2014).

\subsection{Thesis Contribution}

This thesis has made several contributions to understand the effects of various roadway characteristics of bicycle safety. Firstly, this thesis is one of the pioneer studies which explores the application of crowdsourced data to predict bicycle exposure. Secondly, through data fusion of crowdsourced data and video detection data, more accurate data can be obtained to better represent the region of interest. Thirdly, a better understanding to the effects of the various speed management countermeasures on bicycle safety can help policymakers determine an ideal location for these countermeasures. Results suggest that not all speed management countermeasures have the same effect on bicycle safety and must be thoroughly understood before the implementation on roadways.

\subsection{Thesis Objectives}

The objectives can be summarized as below:

- Data fusion between the crowdsourced data and video detection data will be done to create a more accurate dataset.

- A Bayesian joint model was developed to identify the relations between the bicycle crash frequency and factors relating speed management strategies

- Discussion of the parameters in the Bayesian joint model to understand the effects speed management strategies have on bicycle safety. 


\subsection{Thesis Structure}

The thesis is organized into six chapters as follows: Chapter 1 reviews the related studies about bicycle safety and studies that have analyzed the safety measures of various speed management strategies. Chapter 2 presents the data preparation that was done for the bicycle exposure and speed management strategies. Chapter 3 introduces the main methodologies used in this study. Chapter 4 demonstrates the modeling results and discussion. In the end, Chapter 5 summaries the main findings from this thesis and future research directions. 


\section{CHAPTER 2: DATA PREPARATION}

The area of interest, Central Florida, includes context classifications from C1 (Natural) to C6 (Urban Core), as shown in Figure 1. The primarily focus of the study will be urban arterials in Central Florida, thus C4 (Urban General) was selected because of the high level of interaction between cyclist and drivers. The study area also has a relatively high percentage of cyclists and has a high rate of bicycle crashes. Various types of datasets were used for analyzing bicycle safety on C4 roads. These datasets include; bicycle crash data, bicycle volume from STRAVA data, video detection data, and speed management strategies data. Besides, other road attributes, traffic, land use, and socio-demographic variables were also collected.

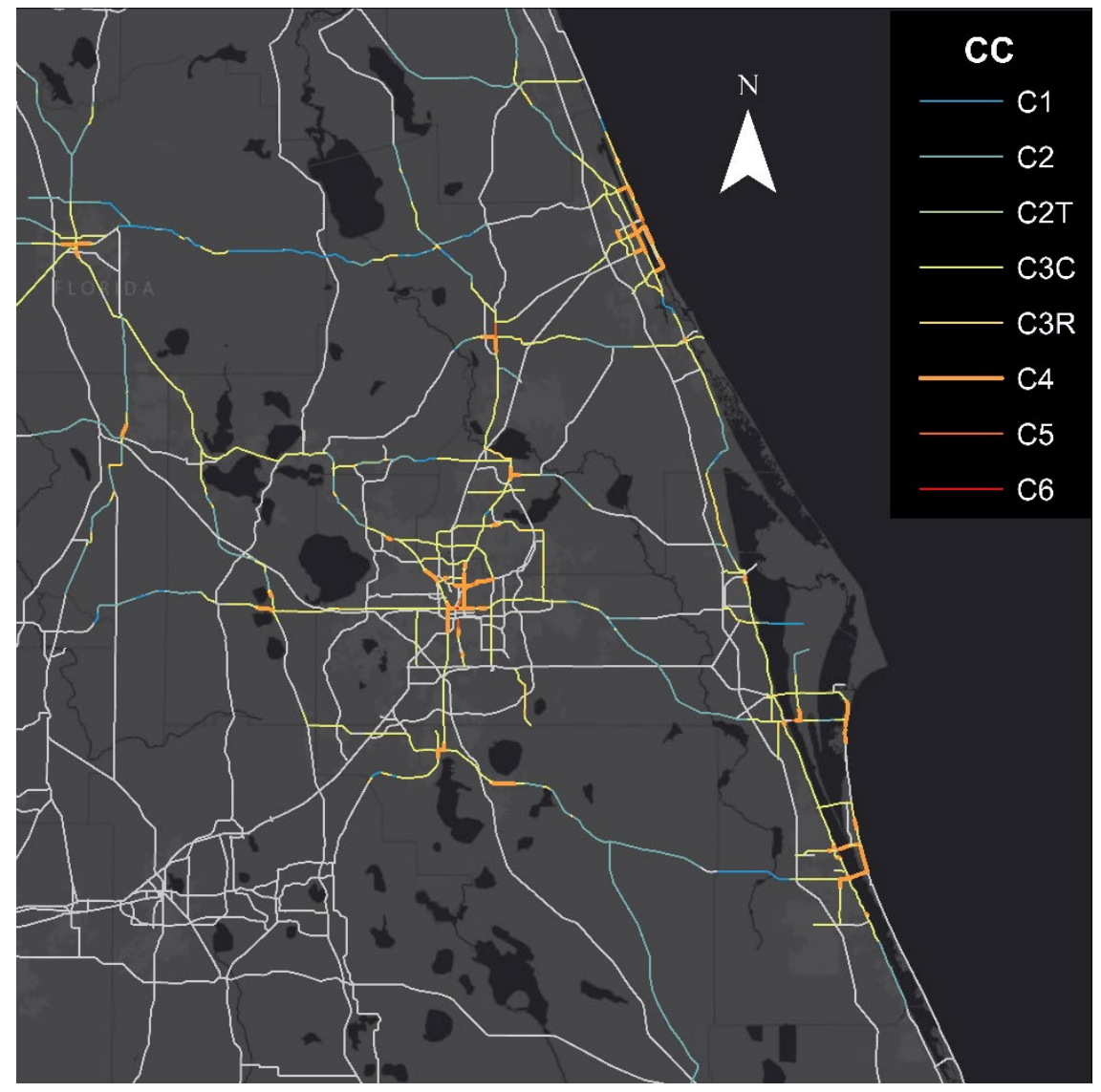

Figure 1 Roads categorized into different context classifications 


\subsection{Bicycle Exposure}

To obtain bicycle exposure two datasets, STRAVA dataset and video detection dataset, had to be utilized to order to insure both coverage and accuracy. The STRAVA dataset was collected through the means of GPS transponders or smart phones that use GPS to record cyclists' trips. STRAVA data was retrieved from January 2018 to July 2018 from the Florida Department of Transportation Unified Basemap Repository (UBR). Figure 2 shows the number of cyclists trips on various road segments in Orlando. The highest number of cyclist trips is near Downtown Orlando, as shown in the top right corner of Figure 2.

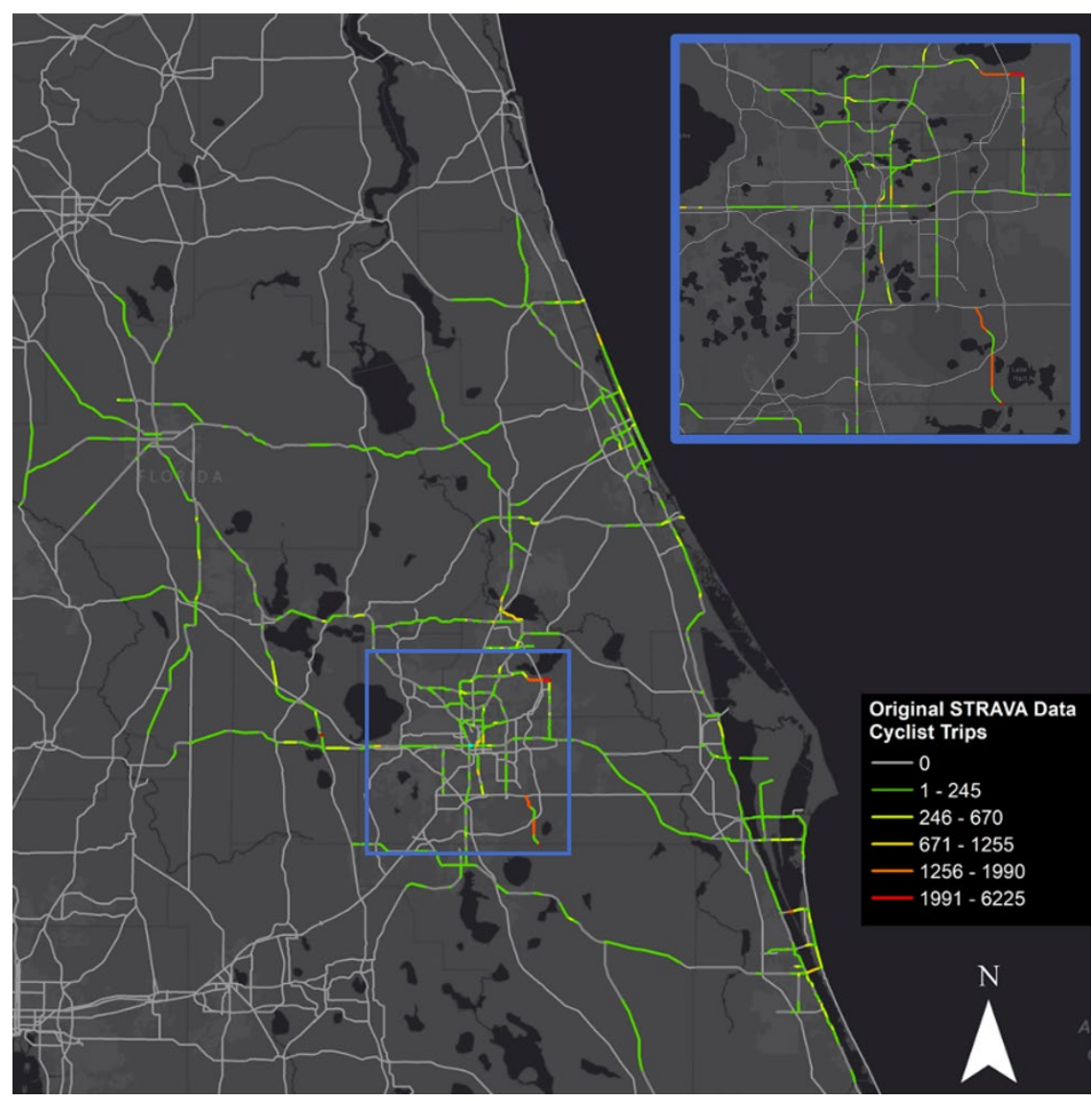

Figure 2 Total cyclist trips from STRAVA between January 2018 to July 2018 
Video detection data was collected at 28 intersections for the month of January in 2019. The intersections that were selected were along major roads in Central Orlando. Each intersection fell within one of the 3 major roads; Orange Blossom Trail, Colonial Drive, and Orlando Avenue.

Video detection data provided the bicycle volumes at each intersection. The bicycle volumes were divided into the respective directions, as shown in Figure 3. Each intersection had volumes for Northbound (NB) Enter, Northbound (NB) Exit, Southbound (SB) Enter, Southbound (SB) Exit, Eastbound (EB) Enter, Eastbound (EB) Exit, Westbound (WB) Enter, and Westbound (WB) Exit. To obtain the volume in the corridor between the two adjacent intersections, the following equations were used. Similar equations were also developed for Northbound and Southbound volumes.

$$
\begin{gathered}
V_{W B}=\frac{W B_{E n t e r, 1}+W B_{E x i t, 2}}{2} \\
V_{E B}=\frac{E B_{E n t e r, 2}+E B_{E x i t, 1}}{2}
\end{gathered}
$$

where

$V_{W B}=$ Volume of the corridor in the Westbound direction

$V_{E B}=$ Volume of the corridor in the Eastbound direction

$W B / E B_{\text {Enter }}=\mathrm{WB} / \mathrm{EB}$ volume entering intersection 1 or 2

$W B / E B_{E x i t}=\mathrm{WB} / \mathrm{EB}$ volume exiting intersection 1 or 2 


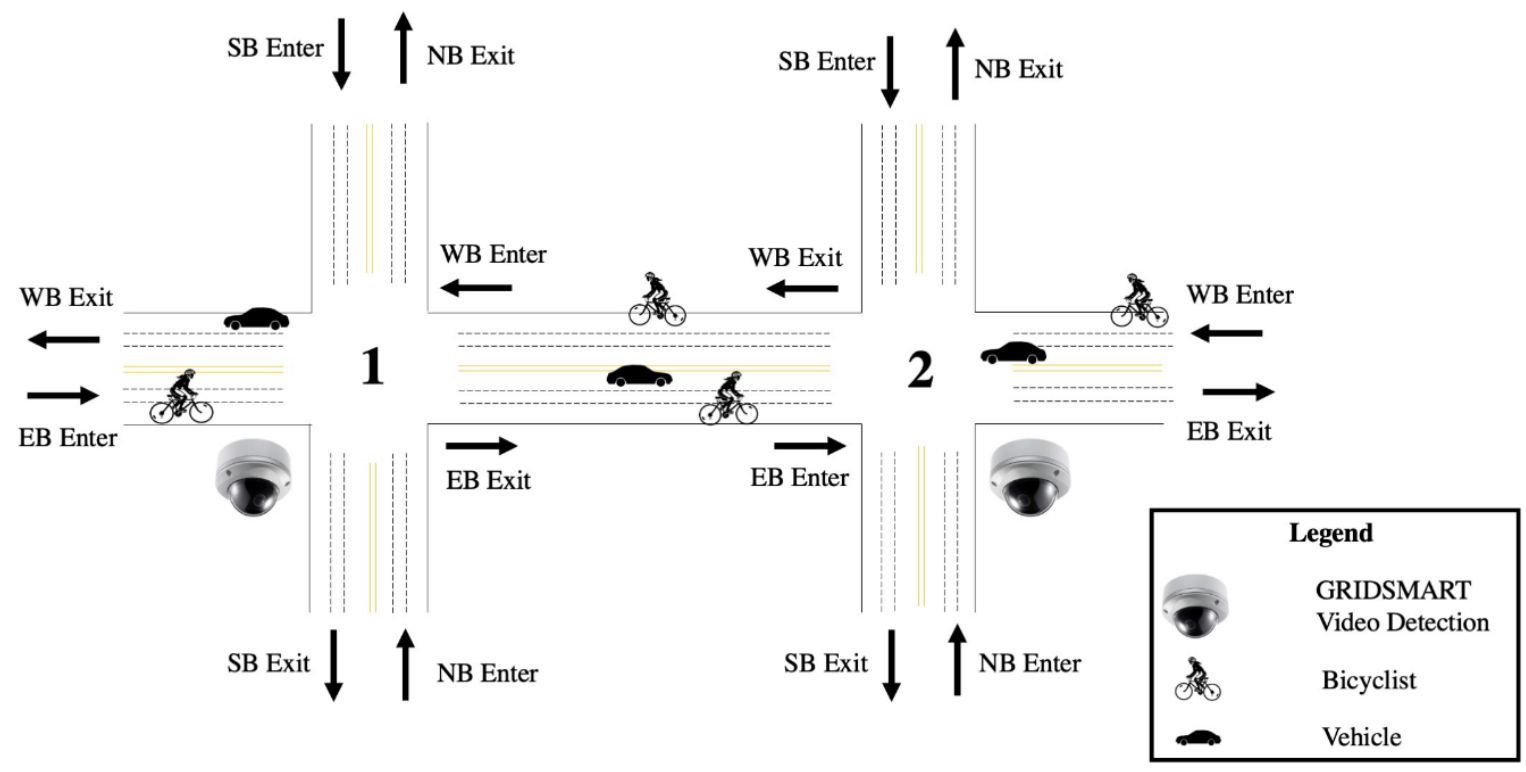

Figure 3 Calculation of bicycle volumes between Intersection 1 and 2 using video detection.

To better represent the true volume of bicycle volumes in the corridors, the STRAVA data was adjusted through the use of the Tobit model. The Tobit model had three explanatory variables (median width, transit frequency, and original STRAVA bicycle volume data), and the output of the model provides the adjusted STRAVA data. The video detection provides the true bicycle volume with an accuracy of greater than 95\% (GRIDSMART, 2019). However, the coverage of video detection is limited since the cameras are only installed at certain intersections in the Central Orlando region. With the adjusted STRAVA data, a much wider range of coverage was obtained. Therefore, through the use of both the adjusted STRAVA data and video detection data, both coverage and accuracy were obtained. 


\subsection{Independent Variables}

To identify the critical contributing factor for bicycle, potential variables were collecting including traffic data, roadway information, land use, and socio-demographic characteristics for each segment.

Table 1 summaries all the potential variables at the segment level with their respective descriptive statistics (mean, standard deviation, minimum value, maximum value). The traffic data was collected from the Florida Department of Transportation (FDOT). The Annual Daily Traffic (AADT), proportion of truck traffic, and daily transit frequency were considered. Fifteen roadway variables related to speed calming strategies were collected, including road surface, number of parking spots, number of parking sides, width of parking, length of parking, number of stop controls, length of stop controls, presence median islands, presence horizontal curves, number bus stops, number of bus bulbs, number of gateways, number of chicanes, presence of two-way left turn lanes, and the length of two-way left turn lanes. All the of variables were collected manually, besides road surface, which was processed based on data from FDOT. Other roadway variables such as speed limit, number of lanes, median width, pavement condition, lane width, sidewalk width, raised median, and out-shoulder were collected from FDOT. The land use attributes were collected from the Florida Department of Revenue. The proportions of residential and commercial lane use was calculated within a 1-mile buffer around the road segment. Sociodemographic variables were collected from FDOT District 5 Transped data, including proportion of population under poverty, proportion of zero-vehicle household, proportion of underage and older population, and proportion of commuters by walking and biking. 
Table 1 Descriptive statistics for the variables

\begin{tabular}{|c|c|c|c|c|}
\hline Variable & Mean & S.D. & Min. & Max. \\
\hline Segment Length (mile) & 0.54 & 0.38 & 0.10 & 1.80 \\
\hline Number of Segments & - & - & 1 & 166 \\
\hline Original STRAVA Cyclist Trips & 98 & 315 & 0 & 6225 \\
\hline GRIDSMART Cyclist Trips & 1334.75 & 994.51 & 163 & 3711 \\
\hline \multicolumn{5}{|c|}{ Traffic Variables } \\
\hline Average Annual Daily Traffic (AADT) & 30998.85 & 9052.96 & 11785.50 & 66833.33 \\
\hline Proportion of Truck Traffic & 6.59 & 3.23 & 1.77 & 16.19 \\
\hline Average Daily Transit Frequency & 20.56 & 18.30 & 0.00 & 72.00 \\
\hline \multicolumn{5}{|c|}{ Roadway Variables Related to Speed Management Strategies } \\
\hline Indicator of Asphalt Road Surface & 0.88 & 0.32 & 0.00 & 1.00 \\
\hline Number of Parking Spots (Left) & 2.49 & 12.55 & 0.00 & 108.00 \\
\hline Number of Parking Spots (Right) & 2.88 & 13.90 & 0.00 & 113.00 \\
\hline Number of Parking Spots (Total) & 5.36 & 26.32 & 0.00 & 221.00 \\
\hline Number of Parking Sides $(0 / 1 / 2)$ & 0.13 & 0.50 & 0.00 & 2.00 \\
\hline Average Parking Width (Left) & 0.46 & 1.74 & 0.00 & 8.00 \\
\hline Average Parking Width (Right) & 0.46 & 1.74 & 0.00 & 8.00 \\
\hline Parking Length (Left) & 52.66 & 265.26 & 0.00 & 2165.00 \\
\hline Parking Length (Right) & 58.28 & 280.93 & 0.00 & 2269.00 \\
\hline Parking Length (Total) & 110.94 & 542.66 & 0.00 & 4434.00 \\
\hline Number of Stop Controls & 1.93 & 1.58 & 0.00 & 8.00 \\
\hline Total Length of Stop Controls & 0.29 & 0.37 & 0.00 & 1.76 \\
\hline Number of Short Blocks & 0.09 & 0.45 & 0.00 & 4.00 \\
\hline Total Length of Short Blocks & 37.98 & 176.42 & 0.00 & 1489.00 \\
\hline Presence of Median Island at Crossing & 0.07 & 0.26 & 0.00 & 1.00 \\
\hline Presence of Horizontal Curves & 0.13 & 0.34 & 0.00 & 1.00 \\
\hline Number of Bus Stops & 3.64 & 5.01 & 0.00 & 33.00 \\
\hline Number of Bus Bulbs (Curb Extension) & 0.23 & 1.18 & 0.00 & 10.00 \\
\hline Number of Gateway (Curb Extension) & 0.01 & 0.17 & 0.00 & 2.00 \\
\hline Number of Chicanes (Curb Extension) & 0.00 & 0.00 & 0.00 & 0.00 \\
\hline Presence of Two-Way Left Turn Lanes & 0.44 & 0.50 & 0.00 & 1.00 \\
\hline Total Length of Two-Way Left Turn Lanes & 0.18 & 0.34 & 0.00 & 1.74 \\
\hline \multicolumn{5}{|c|}{ Other Roadway Variables } \\
\hline Speed Limit (mph) & 39.01 & 4.88 & 30.00 & 55.00 \\
\hline Number of Lanes & 4.39 & 0.80 & 4.00 & 7.00 \\
\hline Median Width & 17.47 & 8.72 & 0.00 & 55.07 \\
\hline Pavement Condition & 4.26 & 0.69 & 3.00 & 5.00 \\
\hline Lane Width & 12.07 & 1.80 & 10.00 & 20.68 \\
\hline Sidewalk Width & 5.41 & 0.96 & 0.00 & 8.26 \\
\hline Raised Median & 0.21 & 0.41 & 0.00 & 1.00 \\
\hline Curb, Out-Shoulder Width & 0.49 & 0.50 & 0.00 & 1.00 \\
\hline \multicolumn{5}{|c|}{$\begin{array}{l}\text { Land Use and Socio-Demographic Variables } \\
\end{array}$} \\
\hline Proportion of Residential Land Use & 0.25 & 0.37 & 0.00 & 1.00 \\
\hline Proportion of Commercial Land Use & 0.04 & 0.10 & 0.00 & 0.81 \\
\hline Proportion of Population Below Poverty & 0.06 & 0.09 & 0.00 & 0.42 \\
\hline Proportion of zero-vehicle household & 0.02 & 0.04 & 0.00 & 0.22 \\
\hline Proportion of underage and older population & 0.16 & 0.20 & 0.00 & 0.73 \\
\hline Proportion of commuters by walking or biking & 0.02 & 0.04 & 0.00 & 0.20 \\
\hline
\end{tabular}




\subsection{Speed Management Strategies Data}

Speed management strategies were collected for the all $\mathrm{C} 4$ roads. In total, five speed management strategies were observed; On-street parking, Short blocks, Horizontal curves, Curb extensions, Pavement surface, and Two-Way Left-Turn Lanes. For on-street parking, the total length of the parking as well as the number of parking spots to the left and right of the road segment was collected. For short blocks, two stop control types were considered; crosswalks and median island at crossing, as well as signalized intersections. If the distance any of three stop control were less or equal to $500 \mathrm{ft}$, it was to be considered a short block according to the Florida Design Manual (FDOT, 2020b). For horizontal curves, any change in the alignment of the road causing limited visibility was considered. For curb extensions, three curb extensions were considered, including gateway, chicane, and bus bulbs. Figure 4 shows the differences between each of the curb extensions. For Pavement surface, two pavement surfaces were considered; asphalt and concrete. The total distance of the continuous Two Way Left-Turn Lanes (TWLTLs) was collected, as shown in Figure 5. 

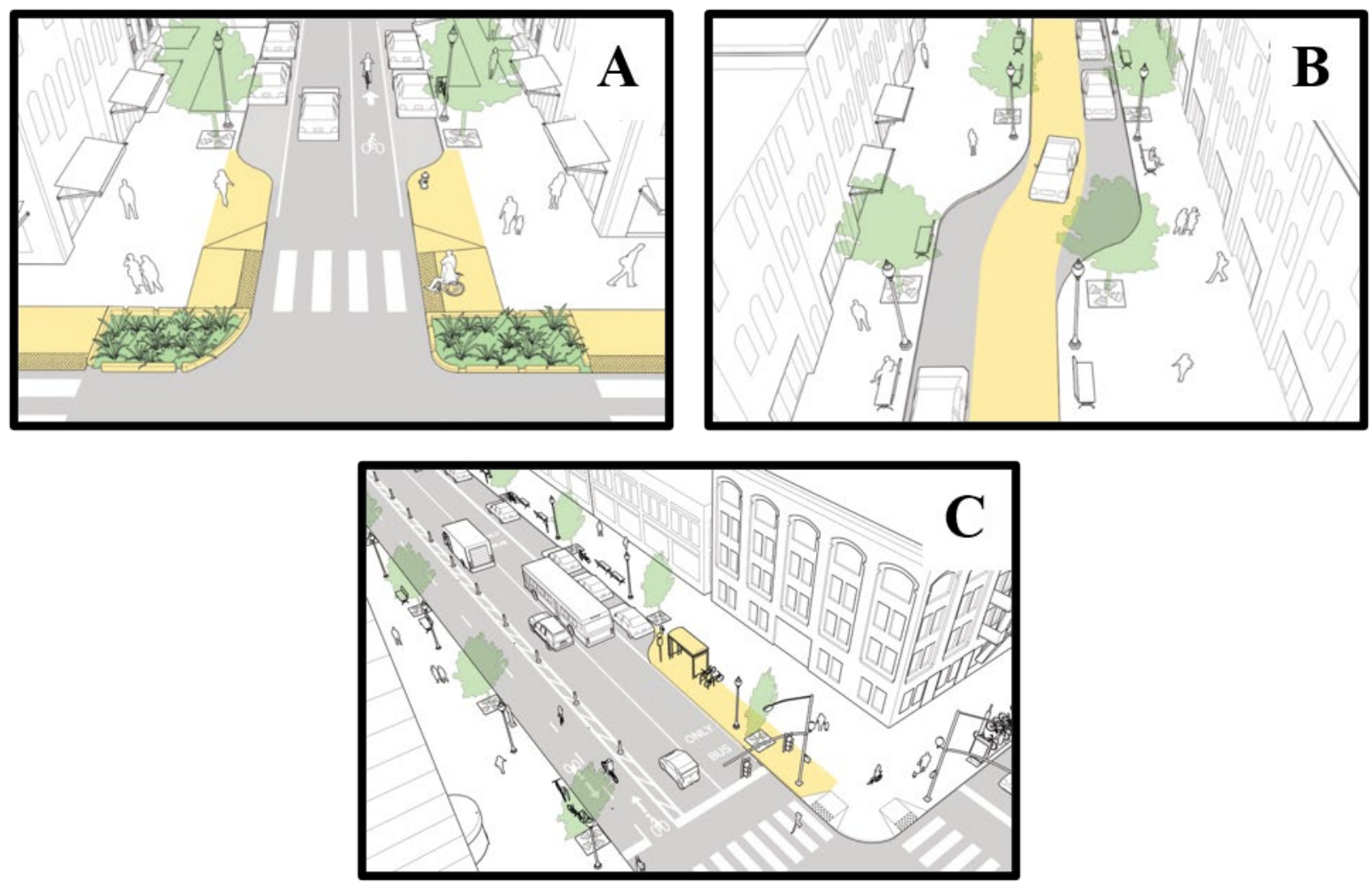

Figure 4 Examples of different types of curb extensions: (A) An example of a gateway, (B) An example of a chicane, (C) An example of a bus bulb (NACTO, 2013)

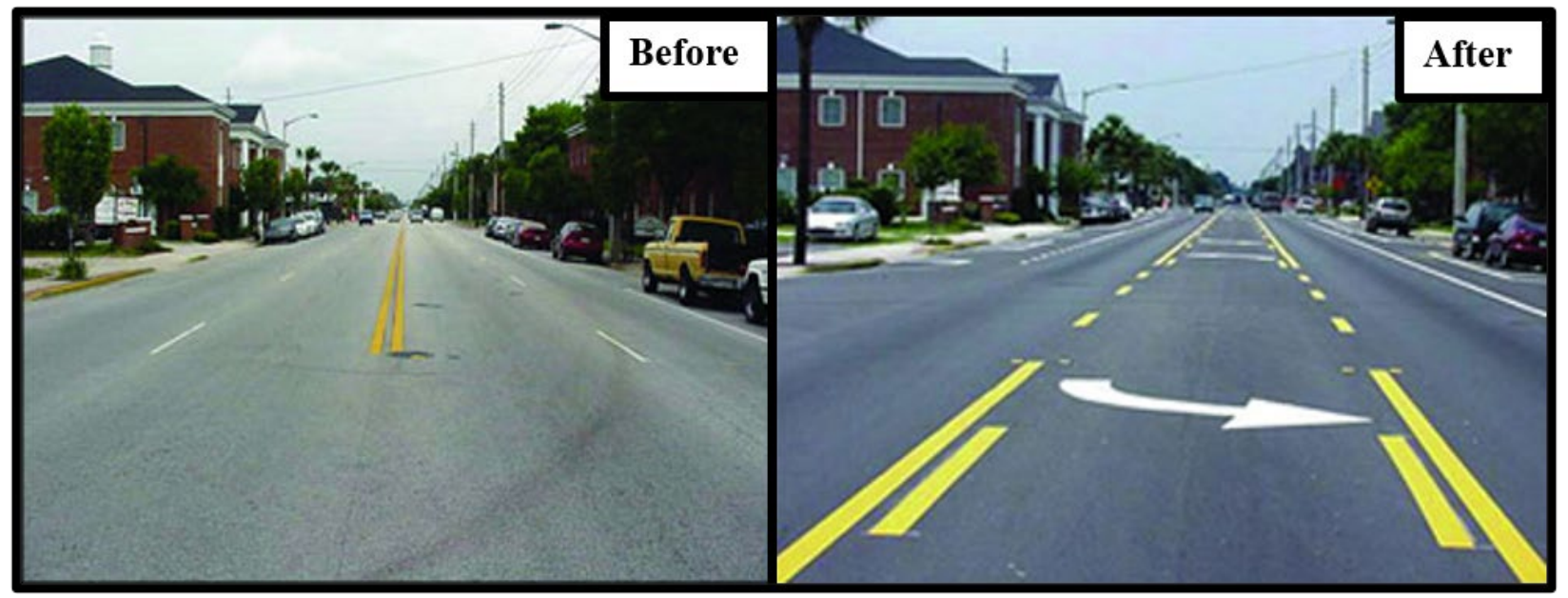

Figure 5 Example of Two-Way Left-Turn Lanes (TWLTLs) (FHWA, 2016) 


\section{CHAPTER 3: METHODOLOGY}

This study attempts to analyze bike crashes on urban arterials considering the speed management strategies and other attributes of roadway geometric, traffic, and land use. To better quantify the effects, the crowdsourced bicycle data STRAVA was used as bicycle exposures and an adjustment was made to overcome the bias of the STRAVA data. Given the fact that the bicycle exposure and bicycle crashes could share some similar factors, a hierarchical Bayesian model was developed to model the bicycle exposure and crashes simultaneously. It was suggested that the integrated model could provide better modeling results than single models (Lee, Abdel-Aty, Cai, Wang, \& Huang, 2018; Strauss, Miranda-Moreno, \& Morency, 2013).

In the previous studies, the Poisson or Poisson-extended models (e.g., negative binomial and Poisson lognormal) have been widely used to analyze the crash counts. The Poisson model assumes that the mean and variance of the variable should be the same. Thus, the Poisson model cannot deal with the over-dispersion (i.e., variance exceeds mean). Both negative binomial model and Poisson lognormal model relax the equal mean variance assumption and allow for overdispersion parameter by adding an error term. Recently, it was indicated that the Poisson lognormal model consistently outperformed the negative binomial model for the crash count analysis (Cai, Abdel-Aty, Lee, \& Eluru, 2017; Strauss et al., 2013). Hence, the Poisson lognormal model was adopted to analyze the bicycle crash count. On the other hand, the Tobit model was applied to adjust the STRAVA data, as suggested by the previous study (Saad et al., 2019).

The STRAVA data was adjusted through the use of a Tobit model. The variables that were input to the model were the median width, transit frequency, and the original STRAVA data. The

output of the Tobit model was is known as the adjusted STRAVA data. The adjusted STRAVA 
data was then considered to be a variable for the Poisson Lognormal Model along with other traffic data, roadway information, and speed management variables.

The Tobit model for bicycle exposure could be formulated as:

$$
\begin{gathered}
y_{i}^{*}=\operatorname{EXP}\left(\beta_{\text {strava }} x_{\text {strava }}+\boldsymbol{\beta} \boldsymbol{x}_{\boldsymbol{i}}\right) \\
y_{i}= \begin{cases}y_{i}^{*}, & \text { if } y_{i}^{*}>0 \\
0, & \text { if } y_{i}^{*} \leq 0\end{cases}
\end{gathered}
$$

where $y_{i}$ is the adjusted bicycle exposure and $y_{i}^{*}$ is the latent variable which is observed only when being positive. $x_{\text {strava }}$ is the STRAVA bicycle volumes and $\boldsymbol{x}_{\boldsymbol{i}}$ is a vector of other explanatory variables. $\beta_{\text {strava }}$ and $\boldsymbol{\beta}$ are the corresponding coefficients.

For bicycle crashes, the Poisson log-normal model could be specified as:

$$
\begin{gathered}
P\left(z_{i}\right)=\frac{E X P\left(-\lambda_{i}\right) \lambda_{i}^{z_{i}}}{z_{i} !} \\
\lambda_{i}=E X P\left(\alpha y_{i}+\Upsilon \boldsymbol{\omega}_{i}+\varepsilon_{i}\right)
\end{gathered}
$$

where $P\left(z_{i}\right)$ is the probability of intersection entity $i$ having $z_{i}$ crashes and $\lambda_{i}$ is the Poisson parameter for intersection entity $i . \boldsymbol{\omega}_{\boldsymbol{i}}$ is the vector of the explanatory variables and $\Upsilon$ is a vector of the corresponding parameters. Besides, $\varepsilon_{i}$ is the error term with the distribution of $\mathrm{N}\left(0, \sigma^{2}\right)$. The adjusted bike exposure $y_{i}$ is fed into the bike crash model and $\alpha$ is the corresponding parameter. Hence, a hierarchical model is developed which could adjust bicycle exposure and model bicycle crash simultaneously. The model parameters were estimated using the Bayesian method (Haque, Chin, \& Huang, 2010; D.-G. Kim, Lee, Washington, \& Choi, 2007; Lee, AbdelAty, Huang, \& Cai, 2019; Serhiyenko, Mamun, Ivan, \& Ravishanker, 2016; Wang \& Huang, 2016; Xie, Wang, Ozbay, \& Yang, 2014). The previous studies have shown the advantages of Bayesian methods in incorporating the complex model structures compared with classical statistical 
modeling methods. In this study, the Bayesian hierarchical model was coded and estimated by using the free statistical software WinBUGS. Three chains were used in the MCMC simulations and each chain contained 10,000 iterations with 5,000 burn-in samples. The models' convergence is evaluated considering several perspectives. First, Brooks-Gelman-Rubin statistics is adopted to check the convergence of multiple chains, where convergence occurs with the value of the statistic less than 1.2 (Spiegelhalter, Best, Carlin, \& van der Linde, 2003). Besides, the convergence is checked by the visual examination of the MCMC trace plots. Finally, the ratios of Monte Carlo errors relative to the respective standard deviations of the estimate are calculated as a measure of convergence. Roughly, convergence is reached when the ratios are less than 0.05 . Non-informative normal $\left(0,10^{6}\right)$ priors were used to run the model. Deviance information criterion (DIC) was used to determine the best combinations of parameters. DIC is a common measurement of Bayesian model comparison and a lower DIC value was preferred. Finally, the significance of the parameter estimation was tested at the $90 \%$ confidence level to include more variables by using Bayesian credible interval (BCI). 


\section{CHAPTER 4: MODELING RESULTS AND DISCUSSIONS}

The results for the Bayesian joint model are shown in Table 2. For the Tobit model, used to adjust the STRAVA bicycle volume data, there were 3 explanatory variables (median width, transit frequency, and original STRAVA bicycle volume data) that were significant within the $90 \%$ confidence level and provided a good model performance. The variables in the Tobit model were categorized into 3 groups; crowdsource data, traffic data, and roadway information. The results of the Tobit model were used as a variable in the Poisson-lognormal model, used to analyze bicycle crashes. For the Poisson-lognormal model, there were 10 explanatory variables that were significant within the $90 \%$ confidence level. The variables in the Poisson-lognormal model were categorized into 4 groups; traffic data, roadway information, speed management strategies, and land use. The selection of these parameters was based on the model performance using DIC. The parameters which had a high correlation were excluded from the model. The spearman rank correlation test has been conducted among all variables. To avoid the adverse impact of correlation, the variables with high correlation (correlation parameter is higher than 0.7 at the significance level of 0.05 ) were not employed in the model at the same time. Figure 6 shows how both models were used. 


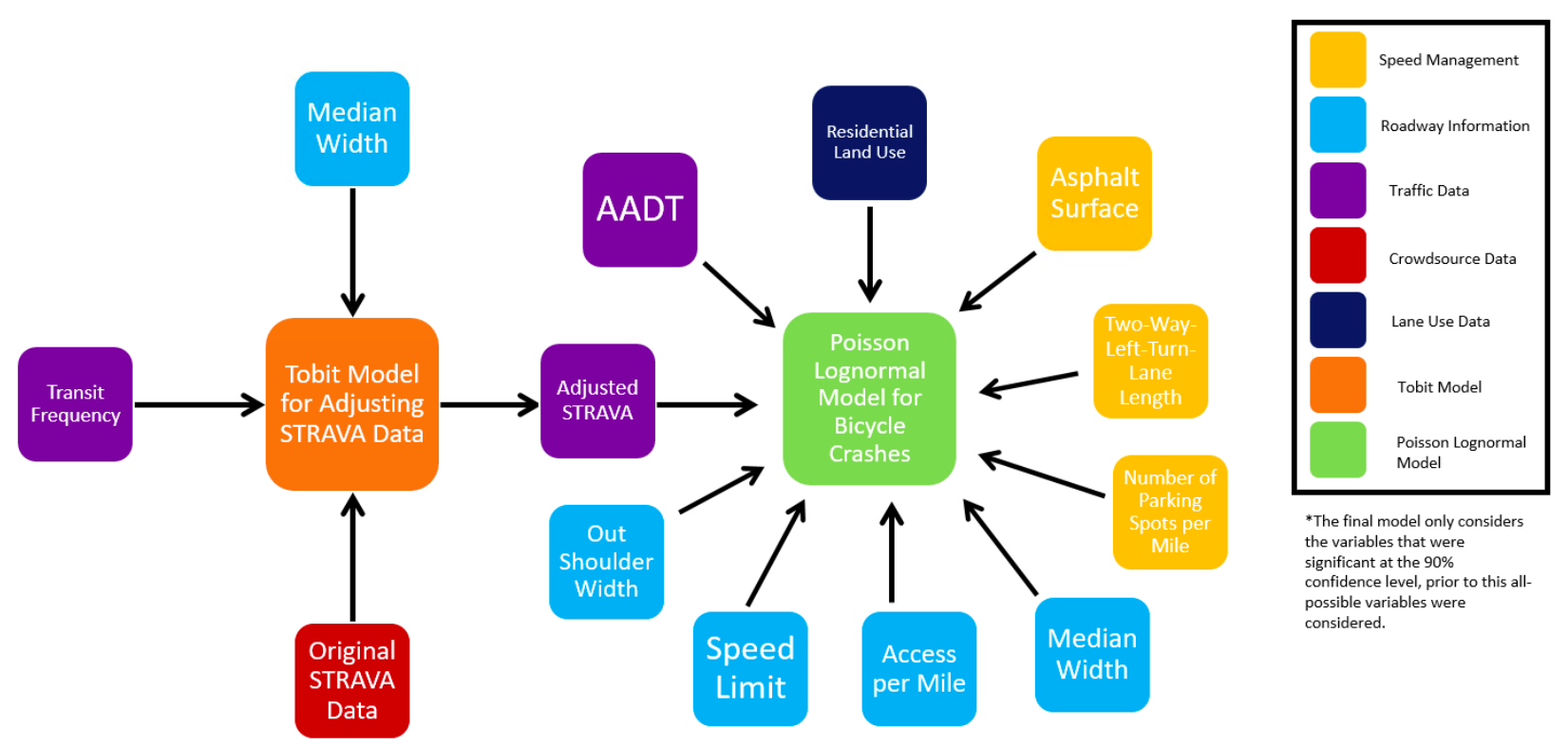

Figure 6 Relationship between the Tobit Model and Poisson Lognormal Model 
Table 2 Bayesian joint model, including the Tobit Model and Poisson Lognormal model

\begin{tabular}{|c|c|c|c|c|c|}
\hline \multicolumn{6}{|c|}{ Tobit Model for Adjusting STRAVA Data } \\
\hline \multicolumn{2}{|r|}{ Variable } & \multirow{2}{*}{$\begin{array}{c}\text { Mean } \\
-5.375\end{array}$} & \multirow{2}{*}{$\begin{array}{c}\text { S.E. } \\
1.229\end{array}$} & \multirow{2}{*}{$\begin{array}{c}5 \% \\
-7.707\end{array}$} & \multirow{2}{*}{$\begin{array}{c}95 \% \\
-2.601\end{array}$} \\
\hline- & Intercept & & & & \\
\hline- & Log of Original STRAVA Data & 0.474 & 0.085 & 0.339 & 0.614 \\
\hline $\begin{array}{l}\text { Roadway } \\
\text { Information }\end{array}$ & Log of Median Width & 3.533 & 0.467 & 2.872 & 4.304 \\
\hline Transit Data & Log of Transit Frequency & 0.286 & 0.064 & 0.184 & 0.389 \\
\hline \multicolumn{6}{|c|}{ Poisson Lognormal Model for Bike Crashes } \\
\hline - & Intercept & -29.550 & 2.133 & -32.520 & -25.490 \\
\hline \multirow{2}{*}{ Traffic Data } & Log of AADT & 1.590 & 0.126 & 1.418 & 1.837 \\
\hline & Log of Adjusted STRAVA & 0.328 & 0.080 & 0.208 & 0.450 \\
\hline \multirow{4}{*}{$\begin{array}{l}\text { Roadway } \\
\text { Information }\end{array}$} & Log of Out shoulder width & -1.269 & 0.261 & -1.682 & -0.835 \\
\hline & Log of Speed limit & 4.597 & 0.490 & 3.646 & 5.193 \\
\hline & Log of Access per mile & 0.740 & 0.169 & 0.507 & 1.049 \\
\hline & Log of Median width & -1.888 & 0.362 & -2.419 & -1.353 \\
\hline \multirow{3}{*}{$\begin{array}{c}\text { Speed } \\
\text { Management }\end{array}$} & Log of Number of parking spots per mile & 0.241 & 0.094 & 0.090 & 0.392 \\
\hline & Log of Two-way-left-turn-lane length & -0.310 & 0.191 & -0.615 & -0.004 \\
\hline & Asphalt Surface (compared to concrete) & -1.091 & 0.288 & -1.552 & -0.637 \\
\hline Land Use & Proportion of residential land use & 0.182 & 0.017 & 0.599 & 0.835 \\
\hline & sd.h & 1.269 & 0.120 & 1.076 & 1.462 \\
\hline & DIC of Tobit Model & \multicolumn{4}{|c|}{387.527} \\
\hline & DIC of NB Model & \multicolumn{4}{|c|}{522.232} \\
\hline & Total DIC & \multicolumn{4}{|c|}{909.759} \\
\hline
\end{tabular}

\subsection{Modeling Results for Traffic Data}

For traffic data, the significant factors were traffic volume and bicycle volume. These variables both had positive coefficients, meaning they were positively associated with bicycle crashes. Therefore, bicycle crashes increased significantly has road segment began to experience higher volumes of vehicle and bicyclist traffic. 


\subsection{Modeling Results for Roadway Information}

For roadway information, the significant factors were out-shoulder width, speed limit, access per mile, and median width. Both speed limit and access per mile were found to be positively associated with bicycle crashes. Road segments that have a higher speed limit, had a greater number of bicycle crashes. Similarly, road segments that had a higher number of access also had a greater number of bicycle crashes. Out-shoulder width and median width were both negatively associated with bicycle crashes. As the width of the out-shoulder and the median are increase, the bicycle crashes decrease. It is also important to note that median width had a greater magnitude, meaning it has a greater impact on reducing bicycle crashes.

\subsection{Modeling Results for Speed Management}

For speed management strategies, the significant factors were on-street parking, two-waylet-turn lanes, and pavement type. On-street parking was found to have a positive association with bicycle crashes. As the number of parking spaces per segment increased, the number of bicycle crashes increased as well. This finding confirms an FDOT study, which found that the presence of parking on both sides, increases bicycle crash probability by $165 \%$ compared to location where on-street parking is not allowed (Alluri et al., 2017). Two-way-left-turn lanes and asphalt pavement has a negative association with bicycle crashes. The more two-way-left-turn lanes there are on a road segment, the less bicycle crashes may occur. This finding confirms a study, that shows a $67 \%$ crash reduction when road diets were implemented (L. Chen et al., 2013). A pavement of asphalt on a road segment may have less bicycle crashes than a road segment with a pavement of concrete. This finding confirms a few studies that have found a relationship between bicycle crashes and pavement type (Dozza \& Werneke, 2014; J.-K. Kim et al., 2007; Robartes \& Chen, 2017). One of the main differences between asphalt and concrete is 
the roughness. A measure the roughness of these pavements is the International Roughness Index (IRI). FHWA states that for new asphalt pavement the typical acceptable IRI values range from 52 to 66 inches/mi. For new concrete the typical IRI values range from 57 to 72 inches/mi (Smith \& Ram, 2016). A higher value for IRI indicates a rougher pavement, therefore smoother pavements, such as asphalt may reduce bicycle crashes, when compared to concrete. It should be noted that IRI provides insights on the effect pavement type has on bicycle crashes, but there are many other pavement condition factors that may be good predictors of cyclist safety. 


\section{CHAPTER 5: CONCLUSIONS}

Due to the low-cost and sustainability of bicycles compared to other modes of transportation, bicycles have become a more popular mode of transport globally. Previous studies have urged for more studies to focus on improving bicycle safety and to provide for recommendations on roadway characteristics. The analysis in this study utilized bicycle crash data, STRAVA data, video detection data, and speed management strategies data for urban (C4) road segments in Central Orlando for a period of 4 years $(2016-2020)$. Previous studies that stated that STRAVA bicycle volume is high correlated to the field bicycle volume. Other studies have some skepticisms towards using STRAVA bicycle volume data, stating that it only represents a sample of cyclists. Therefore, an adjustment had to be made to the STRAVA bicycle volume data by conducting a Tobit model to estimate the total entering bicycle trips. The Poisson Lognormal model reveal that traffic volume, bicycle volume, transit frequency, median width, out shoulder width, speed limit, bicycle access, on-street parking, Two-Way Left-Turn Lanes, and residential land use are all factors that have effect on bicycle crashes.

In general, the findings confirm with the growing number of studies that suggested crowdsourced data could be used to estimate bicycle exposure for roadway segments. In addition, STRAVA data can be adjusted to better estimate the bicycle volume and provide a better model performance. This study contributes to transportation agencies by identifying an efficient way to accurate obtain bicycle volumes and identify roadway characteristics that are critical for enhancing bicycle safety. Transportation engineers and planners should focus on the relationships between the roadway characteristics to better design urban roadways (e.g., utilizing asphalt over concrete when possible, considering lowering the speed limit, increasing the median width when needed, implementing Two-Way Left-Turn Lanes when possible, and avoiding on- 
street parking). The relationship between crash risk and bicycle volume and potential for safety improvements (PSI) and bicycle volume, will also allow transportation engineers and planners improve bicycle safety. For instance, implementing certain bicycle safety measures (e.g., adding a physical barrier between bicyclist and vehicles) on roads depending on the bicycle volume.

The findings of the study will contribute to further studies towards improving bicycle safety through the use of crowdsource data. However, there some improvements that should be considered for future studies. For the study only STRAVA was utilized as a way to obtain the bicycle volumes, other crowdsources data sources could be considered in future studies. Further studies may also consider looking into other context classifications or other road types, to analysis if the same roadway characteristics are significant factors. It should be noted that the variance of locations could introduce the bias to estimate the bicycle exposure based on STRAVA data and camera data. It would be interesting to overcome the bias of locations by considering the population characteristics in the surrounding area of study segments. 


\section{REFERENCES}

Alluri, P., Raihan, M. A., Saha, D., Wu, W., Huq, A., Nafis, S., \& Gan, A. (2017). Statewide analysis of bicycle crashes.

Bauer, K. M., Harwood, D. W., Hughes, W. E., \& Richard, K. R. (2004). Safety effects of narrow lanes and shoulder-use lanes to increase capacity of urban freeways. Transportation research record, 1897(1), 71-80.

Biswas, S., Chandra, S., \& Ghosh, I. (2017). Effects of on-street parking in urban context: A critical review. Transportation in developing economies, 3(1), 10.

Blaizot, S., Papon, F., Haddak, M. M., \& Amoros, E. (2013). Injury incidence rates of cyclists compared to pedestrians, car occupants and powered two-wheeler riders, using a medical registry and mobility data, Rhône County, France. Accident Analysis \& Prevention, 58, $35-45$.

Cai, Q., Abdel-Aty, M., \& Castro, S. (2020). Explore effects of bicycle facilities and exposure on bicycle safety at intersections. International Journal of Sustainable Transportation, 1-12.

Cai, Q., Abdel-Aty, M., Lee, J., \& Eluru, N. (2017). Comparative analysis of zonal systems for macro-level crash modeling. Journal of safety research, 61, 157-166.

Cai, Q., Lee, J., Eluru, N., \& Abdel-Aty, M. (2016). Macro-level pedestrian and bicycle crash analysis: Incorporating spatial spillover effects in dual state count models. Accident Analysis \& Prevention, 93, 14-22.

Chen, J., Li, Z., Wang, W., \& Jiang, H. (2018). Evaluating bicycle-vehicle conflicts and delays on urban streets with bike lane and on-street parking. Transportation letters, 10(1), 1-11. 
Chen, L., Chen, C., Ewing, R., McKnight, C. E., Srinivasan, R., \& Roe, M. (2013). Safety countermeasures and crash reduction in New York City-Experience and lessons learned. Accident Analysis \& Prevention, 50, 312-322.

DiGioia, J., Watkins, K. E., Xu, Y., Rodgers, M., \& Guensler, R. (2017). Safety impacts of bicycle infrastructure: A critical review. Journal of safety research, 61, 105-119.

Ding, H., Sze, N., Li, H., \& Guo, Y. (2020). Roles of infrastructure and land use in bicycle crash exposure and frequency: a case study using Greater London bike sharing data. Accident Analysis \& Prevention, 144, 105652.

Dozza, M., \& Werneke, J. (2014). Introducing naturalistic cycling data: What factors influence bicyclists' safety in the real world? Transportation research part F: traffic psychology and behaviour, 24, 83-91.

FDOT. (2020a). 201 Design Controls.

FDOT. (2020b). 202 Speed Management.

FHWA. (2014a). Engineering Speed Management Countermeasures: A Desktop Reference of Potential Effectiveness in Reducing Crashes.

FHWA. (2014b). Road Diet Informational Guide.

FHWA. (2016). Road Diets (Roadway Reconfiguration).

Fishman, E. (2016). Cycling as transport. In: Taylor \& Francis.

Gates, T. J., Noyce, D. A., Talada, V., \& Hill, L. (2007). The Safety and Operational Effects of ${ }^{\prime \prime}$ Road Diet" Conversions in Minnesota.

GRIDSMART. (2019). Advanced Detection with the Bell Camera. GRIDSMART.

Griffin, G. P., \& Jiao, J. (2019). Crowdsourcing Bicycle Volumes: Exploring the role of volunteered geographic information and established monitoring methods. 
Griswold, J. B., Medury, A., \& Schneider, R. J. (2011). Pilot models for estimating bicycle intersection volumes. Transportation research record, 2247(1), 1-7.

Hamann, C., \& Peek-Asa, C. (2013). On-road bicycle facilities and bicycle crashes in Iowa, 2007-2010. Accident Analysis \& Prevention, 56, 103-109.

Haque, M. M., Chin, H. C., \& Huang, H. (2010). Applying Bayesian hierarchical models to examine motorcycle crashes at signalized intersections. Accident Analysis \& Prevention, 42(1), 203-212.

Hochmair, H. H., Bardin, E., \& Ahmouda, A. (2019). Estimating bicycle trip volume for MiamiDade county from Strava tracking data. Journal of transport geography, 75, 58-69.

Jestico, B., Nelson, T., \& Winters, M. (2016). Mapping ridership using crowdsourced cycling data. Journal of transport geography, 52, 90-97.

Kim, D.-G., Lee, Y., Washington, S., \& Choi, K. J. A. A. (2007). Modeling crash outcome probabilities at rural intersections: Application of hierarchical binomial logistic models. Accident Analysis \& Prevention, 39(1), 125-134.

Kim, J.-K., Kim, S., Ulfarsson, G. F., \& Porrello, L. A. (2007). Bicyclist injury severities in bicycle-motor vehicle accidents. Accident Analysis \& Prevention, 39(2), 238-251.

Kondo, M. C., Morrison, C., Guerra, E., Kaufman, E. J., \& Wiebe, D. J. (2018). Where do bike lanes work best? A Bayesian spatial model of bicycle lanes and bicycle crashes. Safety science, 103, 225-233.

Lee, J., Abdel-Aty, M., Cai, Q., Wang, L., \& Huang, H. (2018). Integrated Modeling Approach for Non-Motorized Mode Trips and Fatal Crashes in the Framework of Transportation Safety Planning. Transportation Research Record: Journal of the Transportation Research Board, 0361198118772704. 
Lee, J., Abdel-Aty, M., Huang, H., \& Cai, Q. (2019). Transportation Safety Planning Approach for Pedestrians: An Integrated Framework of Modeling Walking Duration and Pedestrian Fatalities. Transportation Research Record: Journal of Transportation Research Board, 2673(4), 898-906.

Morrison, C. N., Thompson, J., Kondo, M. C., \& Beck, B. (2019). On-road bicycle lane types, roadway characteristics, and risks for bicycle crashes. Accident Analysis \& Prevention, $123,123-131$.

NACTO. (2013). Urban Street Design Guide.

Neuner, M., Chandler, B., Atkinson, J., Donoughe, K., Knapp, K., Welch, T., . . Crowe, R. (2015). Road Diet Case Studies.

NHTSA. (2019). 2018 Fatal Motor Vehicle Crashes: Overview.

Noland, R. B., Gao, D., Gonzales, E. J., \& Brown, C. (2015). Costs and benefits of a road diet conversion. Case studies on transport policy, 3(4), 449-458.

Nyberg, P., Björnstig, U., \& Bygren, L. (1996). Road characteristics and bicycle accidents. Scandinavian journal of social medicine, 24(4), 293-301.

Petritsch, T. (2009). The influence of lane widths on safety and capacity: A summary of the latest findings.

Robartes, E., \& Chen, T. D. (2017). The effect of crash characteristics on cyclist injuries: An analysis of Virginia automobile-bicycle crash data. Accident Analysis \& Prevention, 104, 165-173.

Saad, M., Abdel-Aty, M., Lee, J., \& Cai, Q. (2019). Bicycle safety analysis at intersections from crowdsourced data. Transportation research record, 2673(4), 1-14. 
Saha, D., Alluri, P., Gan, A., \& Wu, W. (2018). Spatial analysis of macro-level bicycle crashes using the class of conditional autoregressive models. Accident Analysis \& Prevention, $118,166-177$.

Schepers, P., \& den Brinker, B. (2011). What do cyclists need to see to avoid single-bicycle crashes? Ergonomics, 54(4), 315-327.

Schimek, P. (2017). Bicycle Facilities Adjacent to On-Street Parking: A Review of Crash Data, Design Standards, and Bicyclist Positioning.

Schimek, P. (2018). Bike lanes next to on-street parallel parking. Accident Analysis \& Prevention, 120, 74-82.

Serhiyenko, V., Mamun, S. A., Ivan, J. N., \& Ravishanker, N. J. A. m. i. a. r. (2016). Fast Bayesian inference for modeling multivariate crash counts. Analytic methods in accident research, 9, 44-53.

Siddiqui, C., Abdel-Aty, M., \& Choi, K. (2012). Macroscopic spatial analysis of pedestrian and bicycle crashes. Accident Analysis \& Prevention, 45, 382-391.

Smith, K. D., \& Ram, P. (2016). Measuring and Specifying Pavement Smoothness:[techbrief].

Spiegelhalter, D., Best, N. G., Carlin, B. P., \& van der Linde, A. (2003). Bayesian measures of model complexity and fit. Quality control and applied statistics, 48(4), 431-432.

Strauss, J., Miranda-Moreno, L. F., \& Morency, P. (2013). Cyclist activity and injury risk analysis at signalized intersections: A Bayesian modelling approach. Accident Analysis \& Prevention, 59, 9-17.

STRAVA. (2020). Strava Milestones: 50 Million Athletes and 3 Billion Activity Uploads.

Tan, C. (2010). Evaluation of lane reduction “'road diet" "measures on crashes. Washington, DC: US Department of Transportation, Federal Highway Administration. 
Vanparijs, J., Panis, L. I., Meeusen, R., \& de Geus, B. (2015). Exposure measurement in bicycle safety analysis: A review of the literature. Accident Analysis \& Prevention, 84, 9-19.

Wang, J., \& Huang, H. (2016). Road network safety evaluation using Bayesian hierarchical joint model. Accident Analysis \& Prevention, 90, 152-158.

Xie, K., Wang, X., Ozbay, K., \& Yang, H. (2014). Crash frequency modeling for signalized intersections in a high-density urban road network. Analytic methods in accident research, 2, 39-51. 